\title{
RECENT BIOLOGICAL STUDIES RELEVANT TO CARCINOGENESIS
}

\author{
N. A. Cridland, Z. J. Sienkiewicz, C. I. Kowalczuk, and R. D. Saunders \\ NRPB \\ Chilton, Didcot \\ OX11 0RQ, United Kingdom
}

\section{INTRODUCTION}

Technological advance and changing social behaviour have been responsible for driving the massive increase in the production and consumption of electricity during the 20th century. One inevitable consequence of this process has been increased environmental exposure to electromagnetic fields both at work and in the home. While there have been many undoubted benefits from the widespread use of electricity, there has been growing concern, especially during the last thirty years, that prolonged exposure to electromagnetic fields at even low levels could have detrimental consequences on human health, and in particular could be associated with some cancers. This possibility has aroused persistent interest and concern, and continues to be investigated by a substantial number of laboratories throughout the world. Much of this work has been comprehensively reviewed elsewhere (Sienkiewicz, et al, 1991; Saunders, et al, 1991; NRPB, 1992; Cridland, 1993; WHO, 1993), and it is clear that many of the older observations were essentially phenomenological in nature. Within the last few years, however, a more coherent research strategy based on powerful cellular and molecular approaches has started to emerge (Sienkiewicz, et al, 1993).

\section{ELECTRIC AND MAGNETIC FIELDS UP TO $100 \mathrm{kHz}$}

\section{Initiation}

The available evidence suggests that exposure to extremely low frequency (ELF) fields is not genotoxic (Murphy et al, 1993; McCann et al, 1993) and is therefore unlikely to be directly associated with initiation. Although a few studies have reported a higher incidence of chromosome aberrations following exposure to pulsed (Garcia-Sagredo et al, 1990; Khalil and Qassem, 1991) or intermittent (Nordenson et al, 1994) magnetic fields, most recent studies have failed to find any evidence for chromosome aberrations or DNA damage after exposure to $50 \mathrm{~Hz}$ electric fields at up to $20 \mathrm{kV} \mathrm{m}^{-1}$ or magnetic fields at up to 
$5 \mathrm{mT}$ (García-Sagredo et al, 1990; García-Sagredo and Monteagudo, 1991; Livingston et al, 1991; Saalman et al, 1991; Scarfi et al, 1991, 1994; Fiorani et al, 1992; Fairbairn and O'Neill, 1994; Nordenson et al, 1994). In agreement with previous studies using microbial systems, Tabrah et al (1994) found that exposure to $0.2 \mathrm{mT}, 60 \mathrm{~Hz}$ magnetic fields did not affect the mutation frequency in the Ames test; azide-induced mutations, however, were increased by exposure to the magnetic field. The frequency of dominant lethal mutations was not increased in male mice exposed for 14 days to $50 \mathrm{~Hz}$ electric fields at $20 \mathrm{kV} \mathrm{m}^{-1}$ (Kowalczuk and Saunders, 1990).

\section{Tumour Promotion}

A number of studies have examined the possible effects of electromagnetic fields on proliferative responses at the cellular level, as an indicator of tumour promotion. This evidence is considered here at the various stages in the signalling pathways which control cellular behaviour.

Early Signals. A number of cell signalling pathways produce transient increases in the intracellular concentration of free $\mathrm{Ca}^{2+}$, initially by stimulating release from intracellular stores, and subsequently by influx across the cell membrane from the extracellular fluid. A number of studies have sought to investigate the possibility that electromagnetic fields act to stimulate calcium ion movements, and thereby influence signalling pathways. Using rat thymocytes incubated in the presence of ${ }^{45} \mathrm{Ca}^{2+}$, Walleczek and Liburdy (1990) reported that a $22 \mathrm{mT}, 60 \mathrm{~Hz}$ magnetic field increased the influx of $\mathrm{Ca}^{2+}$ which resulted from stimulation with the mitogen Concanavalin A (Con A). In an extension of this work, annular ring dishes were used to expose the cells to different induced electric fields at the same magnetic flux density; the induced current depends on the radius and is therefore larger in the outer rings of such dishes. These experiments indicated that the influx of calcium depended on the induced electric field and demonstrated that the direct application to the culture of a similar electric field produced the same effect (Liburdy, 1992). Furthermore, the fluorescent dye, Fura-2 was used as a probe to make real-time measurements of intracellular free calcium concentration. The data indicated that exposure to a $60 \mathrm{~Hz}$ electric field in the culture of $170 \mathrm{mV} \mathrm{m}^{-1}$ increased the influx of calcium ions from outside the cell, but did not affect release from intracellular stores.

Exposure of Jurkat human lymphoblastic T-cells to a $50 \mathrm{~Hz}, 100 \mu \mathrm{T}$ magnetic field has been reported to elicit an increase in intracellular free $\mathrm{Ca}^{2+}$ concentration which was similar in magnitude to that induced by stimulation with an anti-CD3 antibody (Lindström, et al, 1993). Preliminary reports from other groups using fluorescent indicators to monitor intracellular ion concentrations in Jurkat cells have indicated that the response to a $60 \mathrm{~Hz}$, $2 \mathrm{mT}$ magnetic field (inducing an electric field of $1.8 \mathrm{mV} \mathrm{m}^{-1}$ in the medium), may be dependent on the biological status of the cells (Walleczek et al, 1994). This observation is in agreement with previous findings from the same authors on the Con A-induced calcium response of rat thymic lymphocytes exposed to $3 \mathrm{~Hz}$ pulsed magnetic fields (Walleczek and Budinger, 1992); significant effects on $\mathrm{Ca}^{2+}$ influx were observed at peak flux densities of 6.5 and $28 \mathrm{mT}$, and appeared to be field strength dependent. Exposure of HL-60 human leukaemia cells to complex fields generated in a magnetic resonance imaging unit has been reported to induce a small increase in intracellular free $\mathrm{Ca}^{2+}$ concentration, as monitored using the fluorescent indicator indo-1, (Carson et al, 1990).

It has been reported that ${ }^{45} \mathrm{Ca}^{2+}$ uptake was increased following exposure of a variety of lymphocytic cells to combined static and time-varying magnetic fields 'tuned' to resonant conditions (Lyle et al, 1991; Yost and Liburdy, 1992), although neither of these studies examined the dependence on resonance, for example, by 'detuning' the fields. Furthermore, 
two other studies found that exposure of either human (Prasad et al, 1991) or mouse (Coulton and Barker, 1993) lymphocytes to resonant fields did not affect ${ }^{45} \mathrm{Ca}^{2+}$ uptake or intracellular free $\mathrm{Ca}^{2+}$ concentration respectively.

Effects on the Nucleus. Early reports of increased RNA synthesis from several chromosomes in cultured Sciara coprophilia salivary glands exposed to a variety of ELF magnetic fields (see Goodman and Henderson, 1991) has recently been extended (Goodman et al, 1992) to include an analysis of transcription from the right arm of chromosome 3 in a similar preparation from Drosophila melanogaster. Exposure to a $72 \mathrm{~Hz}$ pulsed magnetic field at a flux density of $3.5 \mathrm{mT}$ has been reported to induce a short-term increase in the synthesis of both total and messenger RNA (mRNA) in CCRF-CEM lymphoblastoid cells (Phillips and McChesney, 1991). Exposure of HL-60 cells to a $1 \mathrm{mT}, 60 \mathrm{~Hz}$ sinusoidal magnetic field was reported to produce a temporally similar, though quantitatively smaller, increase in total RNA synthesis which was dependent on the magnitude of the induced electric field (Greene et al, 1991).

The significance of the reported short-term increases in gross transcription is difficult to assess. Clear and unequivocal evidence for effects on the transcription of specific genes, particularly those known to be important for regulating cellular behaviour would be of far greater importance. Unfortunately the evidence for this is much less convincing. In particular, the absence of internal loading controls renders the data extremely difficult to interpret. Furthermore, the published studies have mostly been based on dot-blots rather than more analytical assays such as Northern blots or RNAase protection assays, and examples of raw data have rarely been shown. Even where the evidence for magnetic field effects on gene expression appears to be reliable, the magnitude of the response tends to be small and should be viewed in the context of the response to other agents. For example, in cultured fibroblasts, c-myc expression can be induced about 20-fold by serum (Campisi et al, 1984), 40-fold by platelet-derived growth factor, 15 -fold by fibroblast growth factor and 10 -fold by the chemical tumour promoter 12-O-tetradecanoylphorbol-13-acetate (TPA) (Kelley et al, 1983). Similarly, treatment of B-lymphocytes with the mitogen lipopolysaccharide results in a 20 -fold induction of c-myc expression, whilst treatment of T-lymphocytes with Con $\mathrm{A}$ elicits a 10-fold induction (Kelley et al, 1983). For the proto-oncogenes c-fos (Shah et al. 1993) and c-jun (Stein et al, 1992), inductions of up to 200-fold have been reported following treatment with serum and ultraviolet radiation respectively. Thus the biological significance of much smaller inductions by EMF must be questionable.

It has been reported that exposure of HL-60 human lymphocytic cells to either pulsed ( $1.5-72 \mathrm{~Hz}, 0.38-19 \mathrm{mT}$ peak) or sinusoidal $(5-150 \mathrm{~Hz}, 0.57-570 \mu \mathrm{T} \mathrm{rms})$ magnetic fields increased accumulation of transcripts from the $\beta$-actin, histone $\mathrm{H} 2 \mathrm{~B}, \mathrm{c}-m y c, \mathrm{c}-\mathrm{src}$, and $\beta$-tubulin genes (Goodman et al 1989, 1992, 1994; Wei et al, 1990; Goodman and Henderson, 1991; Gold et al, 1994); one gene, $\alpha$-globin, did not respond to magnetic fields, but expression of this gene is normally cell-type specific anyway. Exposure to a $5.7 \mu \mathrm{T} \mathrm{rms}$, $60 \mathrm{~Hz}$ sinusoidal magnetic field has also been reported to induce expression of the heat shock protein gene, $h s p 70$ in HL-60 cells (Goodman et al, 1994), and large T antigen in SV40transformed human fibroblasts (Gold et al, 1994). In general these data suggest the existence of frequency, time and field strength windows for magnetic field effects on transcription. However, excessive reliance on the use of dot-blots, and the absence of internal loading controls renders interpretation of these data difficult, if not impossible. Moreover, the results for histone are puzzling since the expression of histones is normally tightly regulated within the cell cycle, whilst the reported increase in accumulation of mRNA from the proto-oncogene c-myc may have little significance since the c-myc gene in these cells is abnormally regulated following a gene amplification event. 
There is some support for magnetic field effects on the expression of c-myc, and other regulatory genes, from work in other laboratories. For example, exposure of CEM-CM3 T lymphoblastoid cells to a $100 \mu \mathrm{T}, 60 \mathrm{~Hz}$ magnetic field for up to 2 hours resulted in transient changes in the expression of the c-myc, c-fos, c-jun, and protein kinase $\mathrm{C}$ (PKC) genes (Phillips et al, 1992). In this study the principle approach was to assess the rate of transcription directly using nuclear run-off assays rather than indirectly by estimating the accumulation of transcripts, a parameter which may be influenced by other processes. Slot-blot analysis of cytoplasmic RNA from the same cells indicated that accumulation gave a reasonable estimate of transcription. In general exposure was reported to increase transcription from the c-fos, c-myc, and PKC genes, whilst the effect on expression of c-jun was variable and dependent on cell density. Time course data indicated that these responses were all observed within an hour, whilst longer exposure was reported to inhibit expression of PKC. It should be noted, however, that in the absence of appropriate internal loading controls it is difficult to reliably assess such small responses (generally around 2-fold).

Effects on gene expression, if they exist, are unlikely to result from direct effects of the applied field on transcription complexes, but would instead result from activation of an appropriate signalling pathway. Data on early signalling events (see above) indicate that there could be effects on calcium ion influx, and it is therefore logical to investigate possible links between this and the activation of genes such as c-myc. Liburdy, et al (1993a) have reported such an association in cultured rat thymocytes stimulated with a suboptimal concentration of Con $\mathrm{A}$ and exposed to a $22 \mathrm{mT}, 60 \mathrm{~Hz}$ magnetic field for 60 minutes. Calcium ion influx and accumulation of $c-m y c$ RNA were measured in the same cells, and whilst both were increased by a combination of magnetic field exposure and suboptimal Con A, neither agent on its own produced an effect. This study appears to have been better conducted than most; c-myc transcripts were quantitated by Northern analysis, and glyceraldehyde-3-phosphate dehydrogenase was used as an internal loading control. However, although this study provides evidence for an association between calcium ion influx and c-myc expression in response to magnetic fields, it does not demonstrate that one leads to the other. It is to be hoped that future extensions to this work will address this question. possibly through the use of appropriate inhibitors and ionophores.

The activation of a gene in response to earlier signalling events occurs as a result of changes in the interaction of protein transcription factors with regulatory elements in the promoter region of the gene. There may be several such elements in the promoters of genes which are responsive to a number of signalling pathways (activated by different stimuli), and identification of the element conferring responsiveness to a particular stimulus may be helpful in elucidating the pathway through which the signal is transduced. It has been reported that a magnetic field responsive element resides between positions -353 and -1257 upstream of the c-myc P1 initiation site (Lin, et al, 1994). The element was identified by deletion analysis of the human c-myc promoter fused to a chloramphenicol acetyl transferase (CAT) reporter gene, and mediated transcriptional activation in HeLa cells exposed to $60 \mathrm{~Hz}$ magnetic fields at $8 \mu \mathrm{T}$, but not $80 \mu \mathrm{T}$. However, 900 base pairs is a relatively large fragment of DNA, and there therefore remains considerable scope for defining the location of the element more precisely. Moreover, it should be noted that the CAT activity appeared to be extremely low for all the constructs, suggesting that they were all essentially unresponsive under the conditions tested.

In contrast to those discussed above, other studies have failed to find consistent effects on proto-oncogene expression. For example, Parker and Winters (1992) examined transcription in a variety of human and mouse cell lines exposed to $0.1 \mathrm{mT}, 60 \mathrm{~Hz}$ magnetic fields and found no evidence for increased accumulation of mRNA from the proto-oncogenes c-fos, c-myc, c-raf and c-ras; there was also no effect on transcription from $h s p 70$ or, in the case of cells infected with either mouse mammary tumour virus or murine sarcoma virus, 
viral genes. It should be noted, however, that in addition to suffering many of the methodological flaws criticised above, the minimum exposure time would have been too long to detect transient effects.

In another study, it was found that exposure of HL-60 cells to a $1 \mathrm{mT}, 60 \mathrm{~Hz}$ field for up to 90 minutes did not affect the accumulation of either c-myc or $\beta$-actin transcripts; the steady state level of the $28 \mathrm{~S}$ ribosomal RNA was also unaffected (Greene et al, 1993). Using a unique assay involving pulse labelling of cellular RNA in combination with a nuclease protection step, it was also shown that the transcription rates for $c-m y c$ and $\beta$-actin were unaffected by exposure. There did, however, appear to be an effect on synthesis of the $45 \mathrm{~S}$ precursor ribosomal RNA, although this appeared to be associated with a concomitant reduction in the half-life of the $45 \mathrm{~S}$ fraction and its mature products the $18 \mathrm{~S}$ and $28 \mathrm{~S}$ RNAs.

A number of studies currently in progress which appear to have been carefully designed and performed, have not yet detected any effect of exposure to magnetic fields. Preliminary reports indicate that in one study accumulation of c-myc RNA was not affected by exposure of HL-60 cells to $60 \mathrm{~Hz}$ magnetic fields at 1 and $10 \mu \mathrm{T}$ (Lacy-Hulbert et al, 1994), whilst in another careful and extensive study, neither c-myc nor $\beta$-actin appeared to be affected by exposure of either HL-60 or Daudi cells to $60 \mathrm{~Hz}$ fields at flux densities from $8 \mu \mathrm{T}$ to $1 \mathrm{mT}$ (Saffer and Thurston, 1994). Similarly, it has been reported that exposure to $50 \mathrm{~Hz}$ magnetic fields at either $6 \mu \mathrm{T}$ or $2 \mathrm{mT}$ did not affect the interleukin-3 induced expression of c-fos, c-jun or jun-B in FDCP-mix murine haemopoietic stem cells (Reipert et al, 1994).

There is some evidence from studies of calcium influx that magnetic field effects on cells are the result of the induced electric field (see above). It is therefore pertinent to consider whether electric fields applied directly to the cultures can affect gene expression. It has been reported that exposure of HL-60 cells to electric fields of $0.3-3 \mathrm{~V} \mathrm{~m}^{-1}$ induced expression of the $c-m y c$, histone $\mathrm{H} 2 \mathrm{~B}$, and $h s p 70$ genes; cells were exposed to frequencies between 15 and $120 \mathrm{~Hz}$ (Blank et al, 1992; Goodman et al, 1994). Under the same conditions, transcription from the $\beta 2$-microglobulin was unaffected. It should, however, be noted that the magnitudes of the reported responses were modest and are therefore of questionable significance.

Effects on Cell Proliferation. Recent studies of DNA synthesis, a measure of cell growth, have failed to establish effects in CCRF-CEM cells exposed to a $3.5 \mathrm{mT}$ magnetic field pulsed at $72 \mathrm{~Hz}$ (Phillips and McChesney, 1991), or HF-19 normal human fibroblasts exposed to a $2 \mathrm{mT}, 50 \mathrm{~Hz}$ field (Cridland et al, 1993). The proliferation of K562 human myeloid leukaemia cells was similarly unaffected by exposure to $50 \mathrm{~Hz}$ electric fields of 20 $\mathrm{kV} \mathrm{m}^{-1}$ (in air) or magnetic fields of $200 \mu \mathrm{T}$ (Fiorani et al, 1992). In contrast, it has been reported that a $14 \mathrm{~Hz}$ electric field of $10 \mu \mathrm{V} \mathrm{m}^{-1}$ applied directly to the culture increased both DNA synthesis and insulin-like growth factor-II (IGF-II) production in TE-85 human osteosarcoma cells (Fitzsimmons et al, 1992). Exposure to a $2 \mathrm{mT}, 50 \mathrm{~Hz}$ magnetic field induced a small but significant increase in several measures of proliferation, although this was dependent on the field generating system (Schimmelpfeng and Dertinger, 1993).

Several studies have been performed under resonant conditions, with the flux density of the static field and the frequency of the time varying field "tuned" for $\mathrm{Ca}^{2+}$ ion resonance. Under these conditions, rabbit-ligament fibroblast proliferation was dependent on the amplitude of the time-varying field, an effect which could be abolished by detuning the static field (Ross, 1990). In another study, the proliferation of 3T3 mouse fibroblasts was increased in a resonant field, whereas human Raji lymphoma cells were unaffected. The proliferation of the human cells could, however, be inhibited by exposure to field conditions which were tuned to $\mathrm{K}^{+}$(Rochev et al, 1990). Exposure of FDCP-Mix murine haemopoietic stem cells 
to a various field conditions, including fields tuned to $\mathrm{Ca}^{2+}$ did not affect proliferation or cell viability (Reipert et al, 1992).

A recent study of ornithine decarboxylase (ODC) activity in L929 mouse fibroblasts indicated that basal activity was elevated by $55-65 \mathrm{~Hz}$ magnetic fields at flux densities of 1-100 $\mu \mathrm{T}$ (Litovitz et al, 1991). The process appeared to be dependent on the maintenance of a coherent signal for at least $10 \mathrm{~s}$.

In Vivo Studies. Tumour promotion has also been examined directly using animal carcinogenesis models. Three studies have employed the well-established mouse skin promotion model. McLean et al (1991) initiated skin tumours in groups of 32 juvenile female SENCAR mice by painting with 7,12-dimethylbenz(a)anthracene (DMBA). Exposure to $60 \mathrm{~Hz}$ magnetic fields at $2 \mathrm{mT}$ for 6 hours a day over 21 weeks did not affect tumour development.

Other studies have investigated whether magnetic field exposure can exert promoting effects on the development of skin tumours in female NMRI (Rannug et al, 1993a) and SENCAR (Rannug et al, 1994) mice. Tumours were initiated in $7-8$ week old mice by painting shaved dorsal skin with DMBA and groups of 30 (NMRI) or 40 (SENCAR) mice were assigned to each treatment. Exposure to $50 \mathrm{~Hz}$ magnetic fields at flux densities of 50 or $500 \mu \mathrm{T}$ commenced one week after initiation and continued for 2 years. Fields were either continuous or intermittent ( $15 \mathrm{~s}$ on/off, SENCAR mice only) and mice were exposed for 19 hours a day (21 hours at weekends). Comparison of exposed animals with control mice, which had received only DMBA, did not reveal any significant differences in either the number of tumour bearing animals or the total number of tumours per group thus demonstrating that magnetic fields do not act as tumour promoters in this system; treatment with the chemical tumour promoter TPA as a positive control greatly enhanced the yield of tumours. These findings were further confirmed by analysis of epithelial hyperplasia, a marker for tumour promotion in mouse skin. In contrast to TPA, which produced a marked hyperplastic response both on its own and in combination with DMBA, magnetic fields did not have any effect.

Exposure to a $20 \mathrm{kHz}, 15 \mu \mathrm{T}$ (peak to peak) pulsed magnetic field did not affect the development of lymphoma in female CBA mice which had previously been exposed to 5.24 Gy of $x$-rays; magnetic field exposure commenced when the mice were 40 days old and continued for the remainder of their lives (Svendenstål and Holmberg, 1993). It should be noted, however, that the high incidence of $x$-ray-induced lymphomas would preclude the detection of magnetic field effects in this study. Exposure to the magnetic field alone did not affect the spontaneous lymphoma incidence although it did significantly decrease survival; the survival data for exposed mice were unusually variable thus casting doubt on the validity of the latter finding.

Three studies have investigated the possibility that magnetic fields might promote the development of mammary tumours initiated with DMBA in female Sprague-Dawley rats. In these studies exposure to magnetic fields started at the time of the first treatment with DMBA and continued for 91 days, at which time the animals were sacrificed for histopathological examination. In one of these studies, a group of 99 rats exposed to a $100 \mu \mathrm{T}$, $50 \mathrm{~Hz}$ field exhibited a significantly higher tumour incidence than controls after 8 weeks of treatment, a trend which continued for the remainder of the exposure (Löscher et al, 1993). The number of tumours per tumour bearing rat was the same for both groups, although the final tumour size was greater in exposed animals. In the other studies, however, groups of 18 - 36 rats which had been exposed to various magnetic fields did not exhibit significant differences in tumour incidence when compared with controls; some measures were altered in individual experimental runs, but these changes were not consistent across the study (Mevissen et al, 1993; Löscher et al, 1994). The field conditions included a $15 \mathrm{mT}$ static 
field, a homogeneous $50 \mathrm{~Hz}$ field of $30 \mathrm{mT}$, and a gradient $50 \mathrm{~Hz}$ field of $0.3-1 \mu \mathrm{T}$. It is possible that small field-dependent effects would not have been detected due to the restricted sample size used in the latter studies (Löscher and Mevissen, 1994).

Beniashvili et al (1991) reported that exposure of rats to a $50 \mathrm{~Hz}, 20 \mu \mathrm{T}$ magnetic field for $3 \mathrm{~h}$ per day enhanced the induction of mammary tumours initiated with nitrosomethyl urea (NMU). Exposure apparently enhanced the rate of tumour development in addition to increasing both the number of rats with tumours and the number of tumours per rat increased. A more complete description of the experimental protocol would, however, be useful for a proper evaluation of this study.

\section{Co-Promotion}

The possibility that magnetic fields may act as tumour co-promoters by enhancing the inhibitory effect of tumour promoters on gap junctional communication, thereby releasing premalignant cells from the inhibitory effect of adjacent normal cells has been investigated. Cain et al (1993a) employed an experimental model in which untransformed mouse fibroblasts inhibit focus formation by transformed cells, an effect which can be relieved by the addition of the chemical tumour promoter 12-0-tetradecanoylphorbol-13-acetate (TPA) to the culture medium. Exposure to a $100 \mu \mathrm{T}, 60 \mathrm{~Hz}$ field for four 1 hour periods every day for 29 days significantly enhanced focus formation by sub-optimal concentrations of TPA. although the effect was not apparent at concentrations of TPA which induced little or no focus formation. It should be noted, however, that there was considerable interexperimental variation. Moreover, preliminary results from the same authors (Cain et al, 1993b) indicated that in an extension to this study $60 \mathrm{~Hz}$ magnetic fields of $1-200 \mu \mathrm{T}$ inhibited rather than enhanced focus formation in a field strength-dependent manner.

Magnetic field co-promotion has also been investigated in a whole animal study (Stuchly et al, 1992). Tumours were initiated in 6 week old female SENCAR mice by painting DMBA onto shaved dorsal skin and promoted by application of a sub-optimal dose of TPA at weekly intervals thereafter. The mice were split into two groups of 48 , one of which was exposed for 6 hours per day and 5 days per week to a $2 \mathrm{mT}, 60 \mathrm{~Hz}$ magnetic field, whilst the other was sham exposed in the same room. The results for the first 24 weeks of the 54 week study indicate that exposure produced a significant increase in the rate of tumour development but not in the yield of tumours at the end of the study. However, preliminary reports from the same authors have indicated that the co-promotion effect is not reproducible and may have been confounded by variable exposure to light (Thansandote et al, 1993). Earlier studies had failed to establish a direct tumour promoting effect of magnetic fields under the same conditions (see above).

Magnetic field exposure does not appear to have any effect on the formation of chemically-induced preneoplastic lesions in rat liver (Rannug et al, 1993b, 1993c). Groups of 9 - 10 male Sprague-Dawley rats were partially hepatectomised and treated 24 hours later with the chemical initiator diethylnitrosamine (DENA).

Rats were exposed to $50 \mathrm{~Hz}$ magnetic fields for 19 hours per day ( 21 hours at weekends), starting one week after initiation and continuing for 12 weeks. After sacrifice of the animals, preneoplastic lesions, characterised by expression of $\gamma$-glutamyl transpeptidase (GGT) and the placental form of glutathione S-transferase (GST), were detected by histochemical staining of liver sections. There were no consistent differences in the number of preneoplastic lesions identified in rats exposed to flux densities between 0.5 and $500 \mu \mathrm{T}$ when compared with unexposed rats; treatment with the chemical tumour promoter phenobarbital increased the yield of preneoplastic lesions almost 20-fold (Rannug, et al, 1993b). Similarly, exposure to magnetic fields at flux densities of 0.5 and $500 \mu \mathrm{T}$ did not have any consistent effect on tumour promotion by phenobarbital in this system (Rannug et al, 1993c). 


\section{Peptide Hormones}

Another avenue whereby exposure to electromagnetic fields could influence tumour promotion is via an effect mediated by circulating peptide hormones. The best developed hypothesis relates to effects mediated by melatonin. This hormone is produced by the pineal gland in a distinct circadian rhythm controlled by the photoperiod: synthesis and secretion of this hormone is high at night and minimal during the day.

Melatonin. Stevens (1987) first suggested that chronic exposure to electric fields may affect melatonin secretion and thereby increase the risk for breast cancer. This possibility has aroused wide interest and attention and produced a large number of reviews, monographs and books on this topic (for example, Gupta et al, 1988; Wilson et al, 1990a; Stevens et al, 1992, Moore-Ede et al, 1992).

Melatonin is known to affect seasonal (reproductive) rhythms, although more recently it has been implicated in a range of other physiological functions, and several possible mechanisms have been proposed which suggest that melatonin may be able to influence oncogenesis, and particularly breast cancer. The most convincing of these suggests that decreased melatonin levels, which cause elevations in circulating estrogen and progesterone and so increase cellular proliferation within the stem cell population of the breast, would increase the risk of cancer of these cells (Cohen et al, 1978). It must also be remembered that significant increases in estrogen concentration would also increase the proliferation of any estrogen-responsive tumour cells. An alternative mechanism suggests that melatonin directly suppresses the growth of (estrogen receptor-positive) tumours (Blask and Hill, 1986; Hill and Blask, 1988). In addition, there is some evidence to suggest that melatonin acts as a scavenger of free radicals (Tan et al, 1993a) and so protects DNA molecules from oxidative damage (Tan et al, 1993b). In this case, reductions in melatonin could increase the likelihood of the initiation of cancers, and possibly of their promotion. To be effective as a radical scavenger, however, melatonin is required at a supraphysiological concentration of about 20 $\mu \mathrm{M}$. This is many orders of magnitude greater than normal serum melatonin concentrations of $100-400 \mathrm{pM}$. For comparison, glutathione, an established radical scavenger which is claimed to be less effective than melatonin, is present in human skin at concentrations of about $1 \mathrm{mM}$. For these reasons, it is possible that only melatonin in pharmacological quantities would provide protection against free radicals. Finally, it is possible that melatonin may have a modulatory effect on immune function (see Stevens et al, 1992) and decreases in circulating melatonin could compromise immune surveillance and leave the animal more vulnerable to carcinogenic attack.

All the proposed mechanisms require that exposure to electromagnetic fields cause reductions in pineal or serum levels of melatonin. However the experimental evidence to support such a statement is somewhat equivocal: some studies have reported an effect, but others have failed to find consistent field-dependent changes in pineal function. This may mean that either the effect is not very robust or it may only occur under highly specific conditions which have yet to be fully described.

Studies using $60 \mathrm{~Hz}$ electric fields (reviewed in Wilson and Anderson, 1990) provided the first indication of a field-dependent effect on pineal function. Suppression of the normal nocturnal rise in the production of melatonin by the pineal gland was observed in adult rats exposed for three weeks to electric fields in the range of $2-40 \mathrm{kV} \mathrm{m}^{-1}$ : normal melatonin rhythms returned within three days of cessation of the field. However, the results were somewhat variable, and magnitude of the effects were independent of field intensity. Similar, if more modest effects have been reported in rats exposed to electric fields from conception until 23 days after birth. In contrast, a more recent study (Sasser et al, 1991) reported that exposure to electric fields failed to modify nocturnal levels of melatonin in adult male and 
female rats. It is of interest to note that the exposure parameters were identical to those used in the previous studies which found positive effects. Similarly, no change in pineal function was found in ewe lambs following chronic exposure to a combined $60 \mathrm{~Hz}$ electric and magnetic field (at $6 \mathrm{kV} \mathrm{m}^{-1}$ and $4 \mu \mathrm{T}$ ) associated with a $500 \mathrm{kV}$ transmission line (Lee et al, 1993). It is possible that the original positive observations were the result of some artifact, possibly associated with the methods used to assay melatonin levels (Reiter, 1993) and may not be related to exposure to the electric field per se. Few attempts to replicate the original findings using electric fields have been made in recent years.

Exposure to magnetic fields has also been reported to disrupt pineal function. A number of studies have found that inversion of the geomagnetic field or exposure to pulsed static magnetic fields modifies nocturnal melatonin metabolism in a variety of rodents (see Reiter, 1993). In contrast, only a handful of studies have investigated the effects of power frequency magnetic fields, and the results are somewhat variable. Chronic exposure to a rotating $50 \mathrm{~Hz}$ magnetic field has been reported to depress both nocturnal and diurnal pineal and serum melatonin levels in albino rats exposed at between 1 and $250 \mu \mathrm{T}$ (spatial vector rms) (Kato et al, 1993) and in pigmented rats exposed at 0.02 and $1 \mu \mathrm{T}$ (Kato et al, 1994a). The unusual exposure conditions appear to limit the relevance of these studies to humans, and exposure to a (more usual) horizontal or vertical field at 0.02 and $1 \mu \mathrm{T}$ was found to be without effect in albino rats (Kato et al, 1994b). As part of an experiment to determine if magnetic fields affect mammary carcinogenesis induced by application of DMBA, albino rats were exposed to a $50 \mathrm{~Hz}$ field at $1 \mu \mathrm{T}$ for $8-9$ weeks (Löscher et al, 1994). This treatment caused a significant but rather conservative reduction in nighttime serum melatonin levels. The effects of DMBA itself on pineal physiology were not described.

Occasionally large, but inconsistent effects have been reported in Djungarian hamsters (Yellon, 1994). An initial experiment found that the nighttime peak of pineal and serum melatonin levels was both reduced and delayed following exposure to a $0.1 \mathrm{mT}$ field for 15 minutes beginning 2 hours before dark, although replicate experiments failed to reproduce these effects, and in one experiment, exposure had no effect on melatonin levels. The differences in responsiveness were attributed to differences in age of subjects and other seasonal factors. No other study has indicated that such a brief exposure before dark could be disruptive to melatonin rhythms, and replication of this study by an independent laboratory appears warranted.

Very few studies appear to have used non-human primates: one preliminary study (Rogers et al, 1991) reported inconsistent changes in serum melatonin levels in baboons exposed to a combined electric and magnetic field (at $30 \mathrm{kV} \mathrm{m}^{-1}$ and $0.1 \mathrm{mT}$ ). With few laboratories possessing the necessary facilities to work with primates, it is important that this study appears in the peer-reviewed literature.

It has not been established that exposure to electromagnetic fields is able to affect the circadian production of melatonin from the pineal in humans, although several large scale investigations are underway to help resolve this issue. The available data are very limited. Wilson et al (1990b) reported a reduction in urinary levels of a stable metabolite of melatonin in some volunteers following nighttime exposure to a very weak $(0.4-0.7 \mu \mathrm{T}) 60 \mathrm{~Hz}$ magnetic field from an electric blanket. The results were highly variable, and were only found in 7 out of 28 subjects, so the robustness of the effect and the implications for human health are not at all clear. It is recognised that individuals exhibit wide differences in sensitivity of melatonin levels to light at night, and it may be that individuals will also show similar differences in sensitivity to electromagnetic fields, although further investigations are required before any firm conclusions can be drawn.

Of more direct relevance to carcinogenesis, Liburdy et al (1993b) investigated whether a $60 \mathrm{~Hz}$ magnetic field could influence the inhibitory effects of melatonin on the growth of cultured breast cancer cells. Growth curves for estrogen receptor- 
positive MCF-7 breast cancer cells were determined over $6-7$ days in the presence or absence of melatonin and magnetic fields. It was found that exposure to the magnetic field did not affect the growth of cancer cells in the absence of melatonin. The presence of melatonin at physiological concentrations $(1 \mathrm{nM})$ produced a small but significant inhibition of cell growth which was abolished by exposure to a $1.2 \mu \mathrm{T}$ field. However, it should be noted that the melatonin-induced growth inhibition was much smaller in magnitude than the variation in growth between subsequent passages of the cells. Despite these limitations, this study is potentially important in that it describes a direct effect of a magnetic field on the interaction of melatonin with cancer cells, although unlike most other studies in this area, the mechanism does not involve an effect on melatonin synthesis or secretion.

Opioids. It is possible to speculate that other polypeptides apart from melatonin could be affected by exposure to electromagnetic fields and possibly lead to an increase in carcinogenic risk. For example, there is good evidence to indicate that exposure to weak magnetic fields can inhibit the functioning of endogenous opioid systems and the actions of exogenous opiate agonists in mice (see Kavaliers and Ossenkopp, 1992). It is therefore of interest to note that endogenous opioids, particularly the pentapepetide [ $\left.\mathrm{Met}^{5}\right]$-enkephalin, have been shown to inhibit the proliferation of murine neuroblastoma cell lines (Zagon and McLaughlin, 1989a) most likely by depressing DNA synthesis and mitosis. Importantly, blockade of the action of these opioids appears to accelerate tumorigenesis and increase cell proliferation (Zagon and McLaughlin, 1989b). It is therefore plausible to consider that exposure to magnetic fields could affect carcinogenic events via field-induced changes in the endogenous opioid systems although this has yet to be demonstrated.

\section{Tumour Progression}

ELF fields could affect tumour progression via changes in immune function. However, exposure of animals to magnetic fields does not appear to result in any significant inhibition of immune responsiveness (Putinas and Michaelson, 1990; Morris et al, 1990). Exposure for 7 days to a $50 \mathrm{~Hz}$ magnetic field at $20 \mathrm{mT}$ did not affect haematocrit values or either total or differential white blood cell counts in mice (Lorimore et al, 1990). In addition, assays of bone marrow stem cells and myelomonocytic progenitor cells failed to reveal significant effects on cell population dynamics, although subtle effects could not be ruled out. McLean et al (1991) examined the effects of exposing mice to a $2 \mathrm{mT}$ magnetic field for $6 \mathrm{~h} /$ day after treatment with DMBA. No effects were observed on mononuclear cell counts, and natural killer cell activities in spleen and blood, or on spleen size, and it was suggested that magnetic fields did not affect the immune response. However, in animals also treated with the tumour promoter TPA exposure to the field resulted in both a greater number of enlarged spleens, and a greater number of mononuclear cells per spleen. Moreover, although mononuclear blood cell count was not significantly increased as a group, it was high in three out of ten animals. The authors interpreted their results as suggesting that magnetic field exposure compromised the animals' immune surveillance thereby reducing its effectiveness in combating tumour growth.

Possible effects on tumour progression have been examined directly. The incidence of leukaemia in a strain of leukaemia-prone mice was unaffected by periodic exposure to a $6 \mathrm{mT}$ magnetic field pulsed at either 12 or $460 \mathrm{~Hz}$ (Bellossi, 1991). The mice were exposed to the magnetic field for 30 minutes twice a week, and leukaemia incidence was studied over five generations of the mice. 


\section{RADIOFREQUENCY FIELDS ABOVE $100 \mathrm{kHz}$ (INCLUDING MICROWAVES)}

\section{Initiation}

A series of reports from one group in particular have indicated that exposure of either Chinese hamster fibroblasts (Garaj-Vrhovac et al, 1990; 1991) or human lymphocytes (Garaj-Vrhovac et al, 1992) to $7.7 \mathrm{GHz}$ radiation at $0.5-30 \mathrm{~mW} \mathrm{~cm}^{-2}$ for up to 60 minutes produced a statistically significant increase in the number of chromosome aberrations. It should, however, be noted that temperature was not actively controlled, and small temperature rises at the surface of the samples were reported. It would appear likely that temperatures within the cultures may have been elevated. Long-term irradiation of mice with $2.45 \mathrm{GHz}$ at an SAR of about $1.2 \mathrm{~W} \mathrm{~kg}^{-1}$ was reported to induce gross DNA rearrangements (Sarkar et al, 1994). In contrast to these results, exposure of Chinese hamster ovary cells to $2.45 \mathrm{GHz}$ radiation at an SAR of $33.8 \mathrm{~W} \mathrm{~kg}^{-1}$ for 2 hours did not produce a nonthermal increase in the number of chromosome aberrations, even in the presence of genotoxic chemicals (Kerbacher et al, 1990).

\section{Promotion}

Membrane Effects. Ion fluxes through the membrane constitute important signalling mechanisms and rely on ion gradients built up by the action of transmembrane ion pumps. A number of reports have suggested that radiofrequency (RF) radiation may be capable of affecting the activity of such pumps. It has been reported, for example, that the human erythrocyte $\mathrm{Na}^{+}, \mathrm{K}^{+}$-ATPase can be induced to pump $\mathrm{Na}^{+}$ion by application of $1 \mathrm{MHz}$ electric fields at $2 \mathrm{kV} \mathrm{m}^{-1}$ (Liu et al, 1990). Another report has suggested that irradiation of a $\mathrm{Na}^{+}, \mathrm{K}^{+}$-ATPase with $9.14 \mathrm{GHz} \mathrm{RF}$ at an SAR of $20 \mathrm{~W} \mathrm{~kg}^{-1}$ generally elevated its activity, although the activity was depressed by irradiation at $25^{\circ} \mathrm{C}$ (Brown and Chattopadhyay, 1991). This observation is consistent with earlier observations that RF irradiation may depress the activity of $\mathrm{Na}^{+}, \mathrm{K}^{+}$-ATPase at temperatures which produced conformational changes in the active site.

Gene Expression. The possible effects of RF and microwave radiation on gene expression have not been thoroughly investigated. One recent study found that exposure of glioma cells to continuous wave (CW) radiation of either $27 \mathrm{MHz}$ or $2.45 \mathrm{GHz}$ resulted in a dose dependent athermal change in gross transcription as measured by incorporation of $\left[{ }^{3} \mathrm{H}\right]$-uridine (Cleary et al, 1990a). Transcription was elevated at an SAR of $25 \mathrm{~W} \mathrm{~kg}^{-1}$, but appeared to be unchanged or even depressed at higher SARs. No effect of frequency was obvious, and the reported effects appeared to persist over a relatively long time. It should be noted, however, that RF radiation at $2.55 \mathrm{GHz}$ has been reported to alter gene expression in a bacterial system by a mechanism which was apparently thermal in nature, despite a gross temperature rise of only $0.1{ }^{\circ} \mathrm{C}$ (Saffer and Profenno, 1992). Hence any reports of altered transcription following exposure at high SARs should be treated with caution.

Proliferation. Athermal effects on the rate of DNA synthesis have been reported following exposure of glioma cells (Cleary et al, 1990a) or human lymphocytes (Cleary et al, 1990b) to either $27 \mathrm{MHz}$ or $2.45 \mathrm{GHz}$ at SARs of $25 \mathrm{~W} \mathrm{~kg}^{-1}$. However, higher SARs resulted in a smaller response, and in some cases actually depressed DNA synthesis. In contrast, athermal exposure to $2.45 \mathrm{GHz}$ radiation has been found not to affect transformation of human lymphocytes in vitro, although thermal exposure enhanced transformation to the 
same extent as conventional heating (Czerska et al, 1992). In the same system, exposure to pulsed fields significantly increased transformation under both thermal and athermal conditions.

Krause et al (1990) have reported that exposure of mouse fibroblasts to $915 \mathrm{MHz}$ amplitude modulated microwaves at an SAR of $3 \mathrm{~W} \mathrm{~kg}^{-1}$ increased ODC activity by 2- to 3 -fold. To put this in perspective it should, however, be noted that phorbol ester treatment and serum stimulation both produced increases of over 20 -fold under the same conditions.

\section{Tumour Progression}

It has been suggested that microwaves may affect tumour progression, and one mechanism for this could involve impairment of the immune system which normally plays a role in preventing tumour development. Veyret et al (1991) reported changes in the antibody responses of mice following repeated exposure to very low level pulsed $9.4 \mathrm{GHz}$ microwaves, amplitude-modulated at $14-41 \mathrm{MHz}$, at an SAR of $0.015 \mathrm{~W} \mathrm{~kg}^{-1}$. The direction of the observed effect appeared to be dependent on the frequency of amplitude modulation.

A recent preliminary report suggested that daily exposure of groups of 44 Fisher 344 rats to either $\mathrm{CW}$, or pulse modulated $915 \mathrm{MHz}$ microwaves did not enhance the growth of brain tumours induced by direct injection of RG2 tumour cells (Salford et al, 1992). Exposures which were for $7 \mathrm{~h} /$ day and 5 days/week started 5 days after inoculation of tumour cells into the head of the right caudate nucleus. Rectal temperatures were monitored before, during and after exposure using an optical temperature device, and were not altered by exposure. Animals were sacrificed after 3 weeks and brains were examined histopathologically.

\section{SUMMARY}

There is no convincing evidence that ELF electric or magnetic fields cause genetic damage and it is therefore extremely unlikely that they could have any effect on the initiation of cancer. It is generally accepted that if these fields do affect carcinogenesis it is likely to be at the level of promotion. This possibility has been investigated at the cellular and subcellular levels, principally by exploring the possibility that cell signalling pathways may be affected leading to increased cellular proliferation. Many of these studies have centred on changes in calcium signalling, whilst others have followed the signalling pathways to the nucleus and examined the expression of proto-oncogenes known to be involved in regulating cellular behaviour. Possible effects on cellular proliferation have been assessed directly and animal carcinogenesis models have been employed to assess the potential for electromagnetic fields to act as promoting agents. Overall, the available experimental evidence remains contradictory and does not provide a clear indication that electromagnetic fields affect tumour promotion. Further studies are required to clarify the situation with respect to putative effects on cellular processes.

There is limited recent evidence suggesting that ELF fields may act as co-promoters, essentially enhancing the effects of chemical tumour promoters, possibly via an effect on cell-cell communication. These studies are, however, at best preliminary, and will need to be both repeated and extended before any firm conclusions can be drawn.

Exposure to electric or magnetic fields has, under some circumstances, been reported to inhibit the night-time synthesis of melatonin, which may have effects on the growth of certain tumours, and this has therefore been suggested as a route by which electromagnetic fields could influence tumour promotion. However, this effect has not always been successfully replicated, and it is possible that the reported changes in melatonin are more attributable 
to the way the samples are collected, stored or analyzed than exposure to electromagnetic fields. Overall, the link between exposure to electromagnetic fields and depression of melatonin levels must remain tentative. Effects mediated by endogenous opioids have been postulated, but have not been demonstrated.

It has been suggested that ELF magnetic fields could affect tumour progression via a suppression of the immune system. There is, however, very little evidence for effects on the immune system and the positive results which have been reported are tentative and do not appear to have been independently replicated.

There is no convincing new evidence that athermal exposure to RF induces genetic damage and thus exposure is unlikely to initiate carcinogenesis. The evidence for effects on ion pumps or cell proliferation, which could constitute a mechanism for influencing tumour promotion, is extremely limited. There is no new convincing evidence that RF irradiation can affect tumour progression.

\section{REFERENCES}

Bellossi, A., 1991, Effect of pulsed magnetic fields on leukemia-prone AKR mice. No-effect on mortality through five generations, Leukemia Res. 15:899-902.

Beniashvili, D. Sh., Bilanishvili, V. G., and Menabde, M. Z., 1991, Low-frequency electromagnetic radiation enhances the induction of rat mammary tumours by nitrosomethyl urea, Cancer Lett. 61:75-79.

Blank, M., Soo, L., Lin. H., Henderson, A. S., and Goodman, R., 1992, Changes in transcription in HL-60 cells following exposure to alternating currents from electric fields, Bioelectrochem. Bioenerget. 28:301309.

Blask, D. E., and Hill, S. M., 1986, Effects of melatonin on cancer: Studies on MCF-7 human breast cancer cells in culture, J. Neural. Transm. 21 (Suppl):433-449.

Brown, H. D., and Chattopadhyay, S. K., 1991, Ouabain inhibition of kidney ATPase is altered by $9.14 \mathrm{GHz}$ radiation, Bioelectromagnetics 12:137-143.

Cain, C. D., Thomas, D. L., and Adey, W. R., 1993a, $60 \mathrm{~Hz}$ magnetic field acts as a co-promoter in focus formation of $\mathrm{C} 3 \mathrm{H} / 10 \mathrm{~T} 1 / 2$ cells, Carcinogenesis 14:955-960.

Cain, C. D., Thomas, D. L., Jimenez, L., Jones, R. A., and Adey, W. R., 1993b, Dependence of $60 \mathrm{~Hz}$ magnetic field strength on copromotion of focus formation, in vitro. IN The Annual Review of Research on Biological Effects of Electric and Magnetic Fields from the Generation. Delivery and Use of Electricity, Savannah, Georgia. 31 October - 4 November.

Campisi, J., Gray, H. E., Pardee, A. B., Dean, M., and Sonenshein, G. E., 1984, Cell-cycle control of c-myc but not c-ras expression is lost following chemical transformation, Cell 36:241-247.

Carson, J. L., Prato, F. S.. Drost. D. J., Diesbourg. L. D.. and Dixon, S. J., 1990, Time-varying magnetic fields increase cytosolic free Ca ${ }^{2+}$ in HL-60 cells, Am. J. Physiol. 259: (Cell Physiol. 28):C687-C692.

Cleary, S. F., Liu, L-M., and Merchant, R. E., 1990a, Glioma proliferation modulated in vitro by isothermal radiofrequency radiation exposure, Radiat. Res. 121: 38-45.

Cleary, S. F., Liu, L-M., and Merchant, R. E.. 1990b, In vitro lymphocyte proliferation induced by radio-frequency electromagnetic radiation under isothermal conditions. Bioelectromagnetics 11:47-56.

Cohen, M., Lippman, M., and Chabner, B., 1978, Role of pineal gland in aetiology and treatment of breast cancer, Lancet 2:814-816.

Coulton, L. A., and Barker, A. T., 1993, Magnetic fields and intracellular calcium: effects on lymphocytes exposed to conditions for 'cyclotron resonance', Phys. Med. Biol. 38:347-360.

Cridland, N. A., 1993, Electromagnetic fields and cancer: A review of relevant cellular studies, Chilton, NRPB-R256, HMSO, London.

Cridland, N. A. Cragg, T. A., and Saunders, R. D., 1993, Proliferative responses of human fibroblasts exposed to ELF magnetic fields. IN Electricity and Magnetism in Biology and Medicine (M Blank, editor) San Francisco, San Francisco Press, pp 628-632.

Czerska, E. M., Elson, E. C., Davis, C. C., Swicord, M. L., and Czerski, P., 1992, Effects of continuous and pulsed $2450-\mathrm{MHz}$ radiation on spontaneous lymphoblastoid transformation of human lymphocytes in vitro, Bioelectromagnetics 13:247-259.

Fairbairn, D. W, and O'Neill, K. L., 1994, The effect of electromagnetic exposure on the formation of DNA single strand breaks in human cells, Cell. Mol. Biol. 40:561-567. 
Fiorani, M., Cantoni, O., Sestili, P., Conti, R., Nicolini, P., Vetrano, F., and Dachà, M., 1992, Electric and/or magnetic field effects on DNA structure and function in cultured human cells, Mutat. Res. 282:25-29.

Fitzsimmons, R. J., Strong, D. D., Mohan, S., and Baylink, D. J., 1992, Low-amplitude, low-frequency electric field-stimulated bone cell proliferation may in part be mediated by increased IGF-II release, $J$ Cell. Physiol. 150:84-89.

Garaj-Vrhovac, V., Horvat, D., and Koren, Z., 1990, The effect of microwave radiation on the cell genome, Mutat. Res. 243:87-93.

Garaj-Vrhovac, V., Horvat, D., and Koren, Z., 1991. The relationship between colony-forming ability, chromosome aberrations and incidence of micronuclei in V79 Chinese hamster cells exposed to microwave radiation, Mutat. Res. 263:143-149.

Garaj-Vrhovac, V., Fu_i_, A.. and Horvat, D., 1992. The correlation between the frequency of micronuclei and specific chromosome aberrations in human lymphocytes exposed to microwave radiation in vitro, Mutat. Res. 281:181-186.

Garcia-Sagredo, J. M., and Monteagudo, J. L., 1991, Effect of low-level pulsed electromagnetic fields on human chromosomes in vitro: Analysis of chromosomal aberrations, Hereditas, 115:9-11.

Garcia-Sagredo, J. M., Parada L. A., and Monteagudo, J. L., 1990. Effect on SCE in human chromosomes in vitro of low level pulsed magnetic field, Environ. Mol. Mutagen. 16:185-188.

Gold, S., Goodman, R., and Shirley-Henderson, A., 1994, Exposure of Simian Virus-40-transformed human cells to magnetic fields results in increased levels of T-antigen mRNA and protein, Bioelectromagnetics 15:329-336.

Goodman, R., Blank, M., Lin, H., Dai, R., Khorkova, O., Soo, L., Weisbrot, D., and Henderson, A., 1994 , Increased levels of hsp 70 transcripts induced when cells are exposed to low frequency electromagnetic fields, Bioelectrochem. Bioenerget. 33:115-120.

Goodman, R., and Henderson, A. S., 1991, Transcription and translation in cells exposed to extremely low frequency electromagnetic fields, Bioelectrochem. Bioenerget. 25:335-355.

Goodman, R., Wei, L-X., Bumann, J., and Henderson, A., 1992, Exposure to electric and magnetic (EM) fields increases transcripts in HL-60 cells: does adaptation to EM fields occur? Bioelectrochem. Bioenerget. 29:185-192.

Goodman, R., Wei, L-X., Xu, J-C., and Henderson, A., 1989, Exposure of human cells to low-frequency electromagnetic fields results in quantitative changes in transcripts, Biochim. Biophys. Acta 1009:216220.

Goodman, R., Weisbrot, D., Uluc, A.. and Henderson, A., 1992, Transeription in Drosophila melanogaster salivary gland cells is altered following exposure to low-frequency electromagnetic fields: Analysis of chromosome 3R. Bioelectromagnetics 13:111-118.

Greene, J. J., Pearson, S. L., Skowronski, W. J., Nardone, R. M., Mullins, J. M., and Krause. D.. 1993, Gene-specific modulation of RNA synthesis and degradation by extremely low frequency electromagnetic fields, Cell. Mol. Biol. 39:261-268.

Greene, J. J., Skowronski, W. J., Mullins, M., Nardone, R. M., Penafiel, M., and Meister, R., 1991, Delineation of electric and magnetic field effects of extremely low frequency electromagnetic radiation on transcription, Biochem. Biophys. Res. Comm. 174:742-749.

Gupta, D., Attanasio, A., and Reiter. R. J., (editors) 1988, The Pineal Gland and Cancer. Tübingen, Brain Research Promotion.

Hill, S. M., and Blask, D. E., 1988, Effects of the pineal hormone melatonin on the proliferation and morphological characteristics of human breast cancer cells (MCF-7) in culture, Cancer Res. 48:61216126.

Kavaliers, M., and Ossenkopp, K-P., 1992, Magnetic fields, opioid systems, and day-night rhythms of behavior. IN Electromagnetic Fields and Circadian Rhythmicity (M. C. Moore-Ede, S. S. Campbell, and R. J. Reiter, editors), Boston, Birkäuser, pp 95-117.

Kato, M., Honma, K., Shigemitsu, T., and Shiga, Y., 1993, Effects of exposure to a circularly polarised 50-Hz magnetic field on plasma melatonin levels in rats, Bioelectromagnetics 14:97-106.

Kato, M., Honma, K., Shigemitsu, T., and Shiga, Y., 1994a, Circularly polarised 50-Hz magnetic field exposure reduces pineal gland and blood melatonin concentrations of Long-Evans rats, Neurosci. Lett. 166:5962.

Kato, M., Honma, K., Shigemitsu, T., and Shiga, Y., 1994b, Horizontal or vertical 50-Hz, 1- $\mu$ T magnetic fields have no effect on pineal gland or plasma melatonin concentrations of albino rats, Neurosci. Lett. 168:205-208.

Kelly, K., Cochran, B. H., Stiles, C. D., and Leder, P., 1983, Cell-specific regulation of the c-myc gene by lymphocyte mitogens and platelet-derived growth factor. Cell 35:603-610. 
Kerbacher, J. J., Meltz, M. L., and Erwin, D. N., 1990, Influence of radiofrequency radiation on chromosome aberrations in CHO cells and its interaction with DNA-damaging agents, Radiat. Res. 123:311-319.

Khalil, A. M., and Qassem, W., 1991, Cytogenetic effects of pulsing electromagnetic field on human lymphocytes in vitro: Chromosome aberrations, sister-chromatid exchanges and cell kinetics, Mutat. Res. 247:141-146.

Kowalczuk, C. I., and Saunders, R. D., 1990, Dominant lethal studies in male mice after exposure to a $50-\mathrm{Hz}$ electric field, Bioelectromagnetics 11:129-137.

Krause, D., Brent, J. A., Mullins, J. M., Penafiel, L. M., and Nardone, R. M., 1990. Enhancement of ornithine decarboxylase activity in L929 cells by amplitude modulated microwaves. IN Abstracts, 12th Annual Meeting of the Bioelectromagnetics Society, San Antonio, Texas, June 1990. p 94.

Lacy-Hulbert, A., Wilkins, R., Metcalfe, J. C., and Hesketh, R., 1994, Quantitative northern analysis of myc gene expression in ELF field-exposed HL60 Cells. IN Abstracts, 16th Annual Meeting of the Bioelectromagnetics Society, Copenhagen. June 1994, p 52.

Lee, J. M., Stormshak, F., Thompson, J. M., Thinesen, P., Painter, L. J., Olenchek, E. G., Hess, D. L., Forbes, R., and Foster, D. L., 1993, Melatonin secretion and puberty in female lambs exposed to environmental electric and magnetic fields, Biol. Reprod. 49:857-864.

Liburdy, R. P., 1992, Calcium signalling in lymphocytes and ELF fields. Evidence for an electric field inetric and a site of interaction involving the calcium ion channel, FEBS Lett. 301:53-59.

Liburdy, R. P., Callahan, D. E., Harland, J., Dunham, E., Sloma, T. R., and Yaswen, P., 1993a, Experimental evidence for $60 \mathrm{~Hz}$ magnetic fields operating through the signal transduction cascade. Effects on calcium influx and c-MYC mRNA induction, FEBS Lett., 334:301-308.

Liburdy, R. P., Sloma, T. R., Sokolic, R., and Yaswen, P., 1993b, ELF magnetic fields, breast cancer, and melatonin: $60 \mathrm{~Hz}$ fields block melatonin's oncostatic action on $\mathrm{ER}^{+}$breast cancer cell proliferation, J. Pineal Res. 14:89-97.

Lin, H., Goodman, R., and Shirley-Henderson, A., 1994, Specific region of the c-myc, promoter is responsive to electric and magnetic fields, $J$ Cell. Biochem. 54:281-288.

Linström. E., Lindström, P., Berglund, A., Mild, K. H., and Lundgren. E., 1993, Intracellular calcium oscillations induced in a T-cell line by a weak $50 \mathrm{~Hz}$ magnetic field, J. Cell. Physiol. 156:395-398.

Litovitz, T. A., Krause, D., and Mullins, J. M., 1991, Effect of coherence time of the applied magnetic field on ornithine decarboxylase activity, Biochem. Biophys. Res. Comm. 178:862-865.

Liu, D-S., Astumian, R. D., and Tsong, T. Y., 1990, Activation of $\mathrm{Na}^{+}$and $\mathrm{K}^{+}$pumping modes of ( $\mathrm{Na} . \mathrm{K}$ )-ATPase by an oscillating electric field, $J$. Biol. Chem. 265:7260-7267.

Livingstone. G. K., Witt, K. L., Gandhi, O. P.. Chatterjee, I., and Roti Roti, J. L., 1991, Reproductive integrity of mammalian cells exposed to power frequency electromagnetic fields. Environ. Mol. Mutagen. $17: 49-58$.

Lorimore, S. A., Kowalczuk. C. I., Saunders, R. D., and Wright. E. G., 1990, Lack of acute effects of $20 \mathrm{mT}$, $50 \mathrm{~Hz}$ magnetic fields on murine haemopoiesis, Int. J. Radiat. Biol. 58:713-723.

Löscher, W., and Mevissen, M., 1994, Animal studies on the role of 50/60-Hertz magnetic fields in carcinogenesis, Life Sci. 54:1531-1543.

Löscher, W., Mevissen, M., Lehmacher, W., and Stamm, A., 1993, Tumour promotion in a breast cancer model by exposure to a weak alternating magnetic field, Cancer Lett. 71:75-81.

Löscher, W., Wahnschaffe. U., Mevissen, M., Lerchl, A., and Stamm, A., 1994, Effects of weak alternating magnetic fields on nocturnal melatonin production and mammary carcinogenesis in rats. Oncology. 51:288-295.

Lyle, D. B., Wang, X., Ayotte, R. D., Sheppard, A. R., and Adey, W. R., 1991, Calcium uptake by leukaemic and normal T-lymphocytes exposed to low frequency magnetic fields, Bioelectromagnetics 12:145156.

McCann, J., Dietrich, F., Rafferty, C., and Martin, A. O., 1993, A critical review of the genotoxic potential of electric and magnetic fields, Mutat. Res. 297:61-95.

McLean, J. R. N., Stuchly, M. A., Mitchel, R. E. J., Wilkinson, D., Yang, H., Goddard, M., Lecuyer, D. W., Schunk, M., Callary, E., and Morrison, D., 1991, Cancer promotion in a mouse-skin model by a $60-\mathrm{Hz}$ magnetic field: II. Tumour development and immune response, Bioelectromagnetics 12:273-287.

Mevissen, M., Stamm, A., Buntenkötter, S., Zwingleberg, R., Wahnschaffe, U., and Löscher, W., 1993, Effects of magnetic fields on mammary tumor development induced by 7,12 -dimethylbenz(a)anthracene in rats, Bioelectromagnetics, 14:131-143.

Moore-Ede, M. C., Campbell, S. S., and Reiter, R. J., (editors) 1992, Electromagnetic Fields and Circadian Rhythmicity, Boston, Birkäuser. 
Morris, J. E., Sasser, L. B., Buschbom, R. L., and Anderson, L. E., 1990, Natural immunity in rats exposed to 60-Hz magnetic fields. IN Project Resumes, DOE Annual Review of Research on Biological Effects of 50 and $60 \mathrm{~Hz}$ Electric and Magnetic fields, November 1990, Denver, Colorado, p A-23.

Murphy, J. C., Kadan, D. A., Warren, J., and Sivak, A., 1993, Power frequency electric and magnetic fields: A review of genetic toxicology, Mutat. Res. 296:221-240.

Nordenson, I., Hansson Mild, K., Andersson, G., and Sandström. M., 1994. Chromosomal aberrations in human amniotic cells after intermittent exposure to fifty Hertz magnetic fields, Bioelectromagnetics 15:293301.

NRPB, 1992, Electromagnetic fields and the risk of cancer. Report of an Advisory Group on Non-ionising Radiation, Doc NRPB, 3, (1) 1-138.

Parker, J. E., and Winters, W., 1992, Expression of gene-specific RNA in cultured cells exposed to rotating 60-Hz magnetic fields, Biochem. Cell Biol. 70:237-241.

Phillips, J. L., Haggren, W., Thomas, W. J., Ishida-Jones, T., and Adey, W. R., 1992, Magnetic field-induced changes in specific gene transcription, Biochim. Biophys. Acta 1132:140-144.

Phillips, J. L., and McChesney, L., 1991, Effect of $72 \mathrm{~Hz}$ pulsed magnetic field exposure on macromolecular synthesis in CCRF-CEM cells, Cancer Biochem. Biophys. 12:1-7.

Putinas, J., and Michaelson, S. M., 1990, Humoral responsiveness of mice exposed to $500 \mu \mathrm{T}, 60 \mathrm{~Hz}$ magnetic field, Bioelectrochem. Bioenerg. 24:371-374.

Prasad, A. V., Miller, M. W., Carstensen, E. L., Cox, Ch., Azadniv, M., and Brayman, A., 1991, Failure to reproduce increased calcium uptake in human lymphocytes at purported cyclotron resonance exposure conditions, Radiat. Environ. Biophys. 30:305-320.

Rannug, A., Ekström, T., Hansson Mild, K., Holmberg, B., Gimenez-Conti, I., and Slaga, T. J., 1993a, A study on skin tumour formation in mice with $50 \mathrm{~Hz}$ magnetic field exposure, Carcinogenesis 14:573-578.

Rannug, A., Holmberg, B., Ekström, and Mild, K. H., 1993c, Rat liver foci study on coexposure with $50 \mathrm{~Hz}$ magnetic fields and known carcinogens, Bioelectromagnetics 14:17-27.

Rannug, A., Holmberg, B., Ekström, T., Hansson Mild, K., Gimenez-Conti, I., and Slaga, T. J., 1994, Intermittent $50 \mathrm{~Hz}$ magnetic field and skin tumour promotion in SENCAR mice, Carcinogenesis 15:153-157.

Rannug, A., Holmberg, B., and Mild, K. H., 1993b, A rat liver foci promotion study with $50 \mathrm{~Hz}$ magnetic fields, Environ. Res. 62:223-229.

Reipert, B., Allan, D., Dale, R. E., and Dexter, T. M., 1992, Interaction of low-frequency, low-intensity electromagnetic fields with haemopoietic stem cells. IN Abstracts, The First World Congress for Electricity and Magnetism in Biology and Medicine, Orlando. Florida. June 1992, p 54.

Reipert, B., Allan, D., Dale, R. E., and Dexter, T. M., 1994, Interaction of low-frequency, low-intensity electromagnetic fields with haemopoietic stem cells. IN Abstracts, 16th Annual Meeting of the Bioelectromagnetics Society, Copenhagen, June 1994, p54.

Reiter, R. J., 1993, A review of neuroendocrine and neurochemical changes associated with static and extremely low frequency electromagnetic field exposure, Integr. Physiol. Behav. Sci. 28:57-75.

Rochev, Yu. A., Narimanov, A. A., Sosunov, E. A., Kozlov, A. N., and Lednev, V. V., 1990, Effects of weak magnetic field on the rate of cell proliferation in culture, Studia Biophysica 135:93-98.

Rogers, W. R., Reiter, R. J., Smith, H. D., and Barlow-Walden, L., 1991, Under some circumstances, combined electric and magnetic field exposure reduces serum melatonin concentration in nonhuman primates. IN Project Resumes, DOE Annual Review of Research on Biological Effects of 50 and $60 \mathrm{~Hz}$ Electric and Magnetic Fields, November 1991, Milwaukee, Wisconsin, p A-26.

Ross, S. M., 1990, Combined DC and ELF magnetic fields can alter cell proliferation, Bioelectromagnetics $11: 27-36$.

Saalman, E., Önfelt, A., and Gillstedt-Hedman, B., 1991, Lack of c-mitotic effects in V79 Chinese hamster cells exposed to $50 \mathrm{~Hz}$ magnetic fields, Bioelectrochem. Bioenerg. 26:335-338.

Saffer, J. D., and Profenno, L. A., 1992, Microwave-specific heating affects gene expression, Bioelectromag netics 13:75-78.

Saffer, J. D., and Thurston, S. J., 1994, Alteration of gene expression by ELF fields. IN Abstracts, 16th Annual Meeting of the Bioelectromagnetics Society, Copenhagen, June 1994, p 54.

Salford, L. G., Brun, A., Eberhardt, J. L., and Persson, B. R. R., 1992, Development of rat brain tumours during exposure to continuous and pulsed $915 \mathrm{MHz}$ electromagnetic radiation. IN Abstracts, The First World Congress for Electricity and Magnetism in Biology and Medicine, June 1992, Orlando, Florida, p 27.

Sarkar, S., Ali, S., Behari, J., 1994, Effect of low power microwave on the mouse genome: A direct DNA analysis, Mutat. Res. 320:141-147. 
Saunders, R. D., Kowalczuk, C. 1., and Sienkiewicz, Z. J., 1991, Biological effects of exposure to non-ionising electromagnetic fields and radiation: III. Radio-frequency and microwave radiation, Chilton, NRPBR240, London, HMSO.

Sasser, L. B., Morris, J. E., Buschbom, R. L., Miller, D. L., and Anderson, L. E., 1991, Effect of $60 \mathrm{~Hz}$ electric fields on pineal melatonin during various times in the dark. IN Project Resumes, DOE Annual Review of Research on Biological Effects of 50 and $60 \mathrm{~Hz}$ Electric and Magnetic Fields, November 1991, Milwaukee, Wisconsin, p A-24.

Scarfi, M. R., Bersani, F., Cossarizza, A., Monti, D., Castellani, G., Cadosi, R., Franceschetti, G., and Franceschi, C., 1991, Spontaneous and mitomycin-C-induced micronuclei in human lymphocytes exposed to extremely low frequency pulsed magnetic fields, Biochem. Biophys. Res. Comm. 176:194200.

Scarfi, M. R., Lioi, M. B., Zeni, O., Franceschetti, G., Franceschi, C., and Bersani, F., 1994, Lack of chromosomal aberration and micronucleus induction in human lymphocytes exposed to pulsed magnetic fields, Mutat. Res. 306:129-133.

Schimmelpfeng, J., and Dertinger, H., 1993, The action of $50 \mathrm{~Hz}$ magnetic and electric fields upon cell proliferation and cyclic AMP content of cultured mammalian cells, Bioelectrochem. Bioenerget. 30:143-150.

Sienkiewicz, Z. J., Kowalczuk, C. I., and Saunders, R. D., 1991, Biological effects of exposure to non-ionising electromagnetic fields and radiation: II. Extremely low frequency electric and magnetic fields, Chilton, NRPB-R239, London, HMSO.

Sienkiewicz, Z. J., Cridland, N. A., Kowalczuk, C. I., and Saunders, R. D., 1993, Biological effects of electromagnetic fields and radiation. IN Review of Radio Science 1990 - 1992 (W. R. Stone, editor) Oxford, Oxford University Press, pp 737-770.

Shah, G., Ghosh, R., Amstad, P. A., and Cerutti, P. A., 1993, Mechanism of induction of c-fos by ultraviolet B (290 - $320 \mathrm{~nm})$ in mouse JB6 epidermal cells, Cancer Res. 53:38-45.

Stein, B., Angel, P., van Dam, H., Ponta. H., Herrlich, P., van der Eb, A., and Rahmsdorf, H. J., 1992, Ultraviolet-radiation induced c-jun gene transcription: two AP-1 like binding sites mediate the response, Photochem. Photobiol. 55:409-415.

Stevens, R. G., 1987, Electric power use and breast cancer: A hypothesis, Am. J. Epidemiol. 125:556-561.

Stevens, R. G., Davis. S., Thomas. D. B., Anderson, L. E., and Wilson, B. W., 1992, Electric power, pineal function, and the risk of breast cancer, FASEB $J$. 6:853-860.

Stuchly, M. A., McLean, J. R. N., Burnett, R., Goddard. M., Lecuyer, D. W., and Mitchel. R. E. J., 1992. Modification of tumour promotion in the mouse skin by exposure to an alternating magnetic field, Cancer Lett. 65:1-7.

Svedenstål, B-M., and Holmberg, B., 1993, Lymphoma development among mice exposed to X-rays and pulsed magnetic fields, Int. J. Radiat. Biol. 64:119-125.

Tabrah, F. L., Mower, H. F., Batkin, S.. and Greenwood, P. B., 1994, Enhanced mutagenic effect of a $60 \mathrm{~Hz}$ time-varying magnetic field on numbers of azide-induced TA 100 revertant colonies, Bioelectromagnetics 15:85-93.

Tan, D-X., Chen, L-D., Poeggeler, B., Manchester, L. C., and Reiter, R. J., 1993a, Melatonin: A potent, endogenous hydroxyl radical scavenger, Endocrine $J .1: 57-60$.

Tan, D-X., Poeggeler, B., Reiter, R. J., Chen, L-D., Chen, S., Manchester, L. C., and Barlow-Walden, L. R., 1993b, The pineal hormone melatonin inhibits DNA-adduct formation induced by the chemical carcinogen safrole in vivo, Cancer Lett. 70:65-70.

Thansandote, A., McLean, J. R. N., Lecuyer, D. W., Davidson, C., Goddard, M. J., and Burnett, R., 1993, The effect of $60-\mathrm{Hz}$ magnetic fields and ambient light on tumour co-promotion in SENCAR mouse skin. IN Abstracts, XXIVth General Assembly of the International Union of Radio Science, Kyoto, Japan, August 25th - September 2nd.

Veyret, B., Bouthet, C., Deschaux, P., de Seze, R., Geffard, M., Joussot-Dubien, J., le Diraison, M., Moreau, J-M., and Caristan, A., 1991, Antibody responses of mice low-power microwaves under combined pulse-and-amplitude modulation, Bioelectromagnetics 12:47-56.

Walleczek, J., and Budinger, T. F., 1992, Pulsed magnetic field effects on calcium signalling in lymphocytes: dependence on cell status and field intensity, FEBS Lett. 314:351-355.

Walleczek, J., Killoran, P. L., and Adey, W. R., 1994, 60-Hz magnetic field effects on $\mathrm{Ca}^{2+}\left(\mathrm{Mn}^{2+}\right)$ influx in human Jurkat T-cells: Strict dependence on cell state. IN Abstracts, 16th Annual Meeting of the Bioelectromagnetics Society, Copenhagen, June 1994, p 76.

Walleczek, J., and Liburdy, R. P., 1990, Nonthermal $60 \mathrm{~Hz}$ sinusoidal magnetic-field exposure enhances ${ }^{45} \mathrm{Ca}^{2+}$ uptake in rat thymocytes: Dependence on mitogen activation, FEBS Lett. 271:157-160. 
Wei, L-X., Goodman, R., and Henderson, A., 1990, Changes in levels of c-myc and histone H2B following exposure of cells to low-frequency sinusoidal electromagnetic fields: evidence for a window effect, Bioelectromagnetics 11:269-272.

WHO, 1993, Electromagnetic Fields ( $300 \mathrm{~Hz}$ to $300 \mathrm{GHz}$ ). Environmental Health Criteria 137, Geneva, World Health Organization.

Wilson, B. W., and Anderson, L. E., 1990, ELF electromagnetic-field effects on the pineal gland. IN Extremely Low Frequency Electromagnetic Fields: The Question of Cancer (B. W. Wilson, R. G. Stevens, and L. E. Anderson, editors), Columbus, Ohio, Battelle Press, pp 159-186.

Wilson, B. W., Stevens, R. G., and Anderson, L. E., (editors) 1990a, Extremely Low Frequency Electromagnetic Fields: The Question of Cancer, Columbus, Ohio, Battelle Press.

Wilson, B. W., Wright, C. W., Morris, J. E., Buschbom, R. L., Brown D. P., Miller, D. L., Sommers-Flannigan, R., and Anderson, L. E., 1990b, Evidence for an effect of ELF electromagnetic fields on human pineal gland function, J. Pineal Res. 9:259-269.

Yellon, S. M., 1994, Acute $60 \mathrm{~Hz}$ magnetic field exposure effects on the melatonin rhythm in the pineal gland and circulation of the adult Djungarian hamster, J. Pineal Res. 16:136-144.

Yost, M. G., and Liburdy, R. P., 1992, Time-varying and static magnetic fields act in combination to alter calcium signal transduction in the lymphocyte, FEBS Lett., 296, 117-122.

Zagon, I. S., and McLaughlin, P. J., 1989a, Endogenous opioid systems regulate growth of neural tumor cells in culture, Brain Res. 490:14-25.

Zagon, I. S., and McLaughlin, P. J., 1989b, Opioid antagonist modulation of murine neuroblastoma: A profile of cell proliferation and opioid peptides and receptors, Brain Res. 498:16-28. 